\title{
Verhoogt zuurstof het comfort tijdens palliatieve sedatie?
}

\section{CASUS}

Sommige verpleegkundigen op de ccu van het

Spaarne Gasthuis geven terminale patiënten zuurstoftherapie bij dyspneu tijdens palliatieve sedatie. Ze menen dat dat prettiger is voor de patiënt. Is dat correct, of beter om dat niet te doen? Verpleegkundigen van de ccu zijn het er niet over eens. De vraag is dan ook: verhoogt zuurstoftoediening het comfort bij terminale, gesedeerde patiënten?

tekst Mireille Vos*

\section{1}

\section{Formuleer je vraag}

( $P=$ patiënt of probleem,

$I=$ interventie, $C=$ vergelij-

king, $O$ = uitkomst)

$\mathrm{P}=$ klinisch opgenomen patiënt, buiten bewustzijn door continue palliatieve sedatie $\mathrm{I}=$ Afzien van zuurstoftherapie tijdens palliatieve sedatie $\mathrm{C}=$ Zuurstoftherapie tijdens palliatieve sedatie $\mathrm{O}=$ Comfort

\section{2}

\section{Zoekstrategie}

Gezocht in Cochrane en Pubmed met de zoektermen (oxygen therapy) OR ("Oxygen/administration and dosage"[Mesh] OR "Oxygen/ therapeutic use" [Mesh] OR "Oxygen/therapy" [Mesh]) AND (palliative sedation OR palliative care OR terminal care OR end of life care) AND (dyspneua OR shortness of breath OR breathlessness). Dit leverde 3 richtlijnen, 1 repeatedmeasure study ${ }^{1}, 1$ comprehensive review ${ }^{2}$ en 1 survey onderzoek ${ }^{3}$ op.

Ook is gezocht in protocollen van het Spaarne Gasthuis, en de richtlijnen van Pallialine, artsenfederatie KNMG en Nederlandse Vereniging voor Intensive Care. Verder gaven een long-/palliatief arts en 2 verpleegkundig specialisten palliatieve zorg bij het Spaarne Gasthuis hun expert opinion.

\section{3}

\section{Beoordeling resultaten}

De onderzoeken zijn van wisselende kwaliteit. Ze zijn beoordeeld met de Cochrane-checklijsten. Volgens de AGREE II-checklist zijn de geraadpleegde richtlijnen ruim voldoende.

\section{Baat bij zuurstof}

In de studie van Cambell ${ }^{1}$ ging het om 32 patiënten tussen de 56 en 97 jaar die terminale zorg kregen. Iedere 10 minuten werd lage zuurstoftoediening, geen zuurstof en medische lucht afgewisseld met de neusbril. Met de Respiratory Distress Observation Scale werd de respiratoire distress bij aanvang en bij elke verandering in de zuurstoftoediening gemeten. $\mathrm{Bij} 6 \mathrm{pa}-$ tiënten ontbraken er waarden vanwege onvoldoende circulatie voor $\mathrm{spO}_{2}$-metingen. De conclusie was dat het routinematig toedienen van zuurstof bij $91 \%$ van de patiënten $(n=32)$ geen significant voordeel opleverde.

\section{Zonder ook comfortabel}

Puntillo et al. ${ }^{2}$ publiceerden een comprehensive review. De zoekstrategie is niet inzichtelijk. De auteurs zijn echter experts op het gebied van palliatieve zorg op de ic. Zij baseerden zich op een groot aantal valide onderzoeken. Ze stellen dat terminale patiënten ook zonder de toediening van zuurstof comfortabel blijven.

Redenen starten of stoppen met zuurstof

Quin-Lee et al. ${ }^{3}$ legden 25 zorgmedewerkers uit diverse functies een vragenlijst voor. Ze werkten allemaal minimaal 2 jaar in een palliatieve zorginstelling. $43 \%$ van de respondenten meende dat zuurstoftherapie het leven ongewenst verlengt. 69\% zei zuurstof te geven omdat de familie erom vraagt, het in het protocol staat of omdat het comfortabel is voor de patiënt. Een andere reden is emotionele steun geven aan familie en/of personeel.

Redenen voor de responden- 
ten om te stoppen met de zuurstoftherapie waren: zuurstof brengt geen comfort of geeft (neus)irritatie, het verlengen van het leven is niet gewenst en het toedienen van zuurstof brengt geen geruststelling voor familie/personeel.

\section{Aanbevelingen}

Zowel in de KNMG-,

NVIC- als de Pallialine-richtlijn staat dat morfine de voorkeur heeft voor de behandeling van dyspneu. De richtlijn van Pallialine, het artikel van Campbell en van Puntillo vermelden dat zuurstoftherapie alleen geïndiceerd moet worden als er sprake is van hypoxie. In andere gevallen is deze therapie niet wenselijk, omdat zuurstoftoediening onnodig het leven verlengt, geld kost zonder effect te behalen en irritatie in het neusgebied kan veroorzaken.

De NVIC stelt echter dat zuurstoftherapie ook bij hypoxie het leven ongewenst verlengt. Positief is dat de therapie bij hypoxie tot sufheid zou leiden, wat als een natuurlijk sedativum gezien kan worden. Waarschijnlijk geldt dit alleen als de patiënt diephypoxisch is.

Pallialine stelt dat patiënten in de stervensfase niet goed kunnen ademen, waardoor hypercapnie ontstaat. Hierdoor verlaagt het bewustzijn en verdwijnt het gevoel van dyspneu. Zuurstoftherapie is dus niet gewenst.
Volgens de NVIC-richtlijn en onderzoeker Campbell wordt zuurstoftherapie ingezet om het subjectieve benauwdheidsgevoel of de dyspneu geassocieerde respiratoire distress te verminderen. De vraag is of de patiënt hier, door het verlaagde bewustzijn, hinder van ondervindt. Wel kan de benauwdheid voor naasten belastend zijn.

De geraadpleegde experts in het Spaarne Gasthuis bevestigen dat zuurstoftherapie bij een continu gesedeerde patiënt niet pallieert en mogelijk levensverlengend werkt. De patiënt zal geen hinder van de dyspneu ondervinden bij afwezigheid van bewustzijn. Eén expert geeft aan dat de wimperreflex gebruikt kan worden om het bewustzijn van de patiënt te toetsen. Zonder wimperreflex kan zuurstoftherapie gestopt worden.

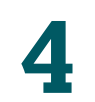

\section{Conclusie}

De bevindingen zijn niet eenduidig. Met name zuur-

\section{nursing/congressen}

\section{MASTERCLĀSS EBP}

Ga een hele dag aan de slag met EBP en word nog beter in het beoordelen van evidence. Op dinsdag 26 oktober organiseert Nursing een Masterclass EBP in Ede. Je leert onder meer welk onderzoek je wel of juist niet kunt gebruiken en hoe je de vertaalslag maakt naar de praktijk. Meer informatie: www.nursing.nl/congressen/ebp.

stoftoediening bij hypoxische patiënten is onderwerp van discussie. Bij niet-hypoxische dyspneu zijn de onderzoekers het erover eens dat de zuurstoftherapie gestaakt kan worden. Gaat het om dyspneu tijdens het toedienen van continue palliatieve sedatie, dan gaat de voorkeur uit naar de behandeling met morfine.

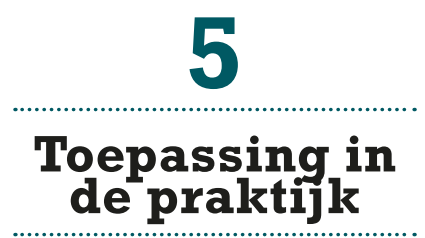

De aanbevelingen zijn toepasbaar en uitvoerbaar op de ccu van het Spaarne Gasthuis.
Dat is besloten na overleg met de longarts en physician assistent van de afdeling. Gezien de recente publicatie van deze CAT en de focus op covid-19, zijn de aanbevelingen nog niet geïmplementeerd.

*Mireille Vos is EBP-expert i.o. in het Spaarne Gasthuis in Haarlem. De CAT is mede gebaseerd op onderzoek van Wouter Weyland, Yan Kranenburg en Karlijn Klinkert-Kosters, verpleegkundigen op de ccu/ehlh (eerste hart long hulp) in het Spaarne Gasthuis in Haarlem.

Contact:mvos@spaarnegasthuis.nl I Dit artikel is een ingekorte versie van het origineel.

\section{Noten}

1 Campbell ML, Yarandi H, Dove-Medows. Oxygen is nonbeneficial for most patients who are near death. Journal of pain and symptom management 2013;45(3):517-523.
2 Puntillo K, Nelson EJ, Weissman, et al. Palliative care in the ICU: relief of pain, dyspnea, and thirst - A report from the IPAL-ICU advisory board.
Intensive care med 2014; 4O(2):235-248

3 Quinn-Lee L, Weggel J, Mosh DS. Use of Oxygen at the End of Life: Attitudes, Beliefs, and Practices in Wisconsin 2018; 117(1):7-13. 